\title{
УПРАВЛЕНЧЕСКОЕ ПPABO
}

Дойников И.В.

\section{ОПЫТ ГОСУДАРСТВЕННОГО СТРОИТЕЛЬСТВА В СССР И В КИТАЙСКОЙ НАРОДНОЙ РЕСПУБЛИКЕ}

\begin{abstract}
Аннотация: Предметом статьи являются правовые и организационные проблемы государственного строительства в СССР и КНР. Объектом статьи является круг общественных отношений связанных с реформирование экономики и социальной сферы в системе государственного управления. Автор статьи особое внимание обращают на формы и методы реформирования государственного управления в СССР и Китайской Народной Республики. Особое внимание в статье уделяется теории рассматриваемой проблемы, а также тех системных ошибках, которые были сделаны в ходе государственного управления в период перестройки. Методологическую основу статьи составили современные достижения теории познания. В процессе исследования применялись общефилософский, теоретический методы (диалектика, системный метод, анализ, синтез, аналогия, дедукция, наблюдение), традиционно правовые методы, а также методы, используемые в конкретно-социологических исследованиях. Основные выводы, которые сделаны в ходе исследования, касаются совершенствования правовых организационных проблем государственного управления. Новизна статьи заключается в том, что в ней с различных позиций дана комплексная оценка перестройки времен 80-х годов XX в. Особым вкладом статьи является то, что в ней продолжается изучение системного кризиса постсоветского правоведения, начатого автором в предыдущих изданиях, где системно были раскрыты некоторые проблемы современной российской государственности и изложены в Программе курса «Проблемы государства и права переходного периода».

Ключевые слова: управление, КНР, перестройка, система, кризис, право, государство, власть, реформа, реформирование.

Review: 1. The article focuses on the legal and organizational problems of state building in the USSR and China. The object of the article is the circle of social relations associated with reforming of the economy and social sphere in the system of public administration. The author of the article pays special attention to the forms and methods of public administration reform in the USSR and the People's Republic of China. Special attention is paid to the theory of the problem, as well as to the system mistakes that had been made in the public administration in the period of perestroika. 2. The methodology of the research is based on the modern achievements of epistemology. The author uses the general philosophical and theoretical methods (dialectics, the system method, analysis, synthesis, analogy, deduction, observation), the traditional legal methods and the methods used in special sociological research..3. The main conclusions of the study relate to the improvement of legal organizational problems of public administration. The novelty of the paper lies in the fact that from various positions it gives a comprehensive assessment of the restructuring of the times of the 1980s. Special contribution of the article is that it continues the study of the system crisis of the post-Soviet law, initiated by the author in previous publications, where he had systematically revealed some problems of modern Russian statehood and set them out in the Programme of the course "Problems of state and law in transition".

Keywords: reform, power, government, law, crisis, system, perestroika, China, management, reforming.
\end{abstract}

1. Итоги перестройки в СССР. Одной из составляющих «перестроечной мифологии» - это идея западничества, европейского выбора, вхождения страны (СССР, потом России) в число стран современной западной цивилизации.

Эта идея тоже имела два важных аспекта - создание современной рыночной экономики (как на
Западе) и политическое сближение с ним (включая разоружение, окончание холодной войны).

Кроме ограниченной группы городских либералов, «русских европейцев», сохранившихся и поныне, эта идея получила в своё время и массовую поддержку (вспомним ту же программу «500 дней») различных слоёв населения. Они рассчиты- 
вали на быстрое установление «потребительского рая» или хотя бы на элементарное наполнение пустых прилавков товарами.

Обе эти идеи тоже если и не провалились, то оказались сильно задвинуты из первых рядов в последние. Развитие рынка уже в послегорбачёвские времена натолкнулось на непреодолимые препятствия и культурного, и экономического характера, о которых надо говорить отдельно. А «медовый месяц» отношений с Западом перерос в новое издание холодной войны, опирающееся на идейный консенсус уже нынешнего российского общества. Сделать Россию Западом не только не получилось, но более того - мы видим глубокий откат даже от зыбкого состояния взаимного движения, которым отмечено начало перестройки во времена Рейгана и Тэтчер [1].

В чём же состоит причина перехода инициативы преобразований к сторонникам радикальной трансформации в сторону Запада и рынка в конце 80-х? Почему эта группа, которая и сегодня, и в то время составляла не более 30 процентов общества, сумела навязать свой политический и экономический сценарий? Были ли иные варианты развития политических процессов?

На этот вопрос история пока не смогла дать однозначного ответа.

Одновременно были распущены первые и последние в новейшей истории России демократические Советы всех уровней, которые в период 19901993 годов явились сосредоточением реальной низовой активности масс при всей своей внешней безалаберности. Режим снова предпочёл опереться не на народ, не на национально мыслящую элиту, а на горстку фаворитов.

Аналогично, одной из основных причин поражения перестройки, сужения её социальной базы стала неготовность авторов перестройки опереться на национально ориентированные слои российского общества и его культурной элиты. Уже к концу 1987 г. перестройка приобрела явно антинациональные черты, которые оттолкнули от неё эти слои. А прозападные силы, оставшиеся в качестве основной социальной базы, сдали Горбачёва и его перестройку вместе с идеей социализма, пусть гуманного и демократического.

Таким образом, перестроечный консенсус на ранней стадии был обусловлен объединением двух массовых тенденций в общественном мнении и идеологии - сторонников быстрейшего вхождения в Запад («западников») и сторонников «обновлённого социализма», восстановления принципов социальной справедливости, узурпированных тогдашней партийно-государственной номенклатурой. Понятно, что рано или поздно подобный союз должен был распасться.

1989 год, особенно его первая половина, ознаменовавшаяся Первым съездом народных депутатов, был, пожалуй, последним триумфом перестройки и лично Горбачёва. Одновременно этот период стал началом конца перестройки. Уже во второй половине года инициатива реформирования СССР стала стремительно переходить к иным политическим силам. Горбачев оказался в арьергарде набиравших силу разрушительных революционных процессов.

Перестройка как таковая оказалась зажатой между двух тенденций и связанных с ними политических сил - тех, кого пугали и не устраивали происходящие события, и тех, кто, напротив, стремился их ещё более ускорить и радикализировать. По сути дела, именно с 1989 года идеи перестройки оказались приватизированы лишь радикальными прозападническими группами советской элиты и интеллигенции.

Сегодня, оценивая перестройку «задним числом», в качестве основных дилемм, стоящих тогда и перед властью, и перед обществом, мы видим следующие:

- сохранить социалистический строй в «обновлённом виде», построить «демократический социализм с человеческим лицом», что, собственно, и составляло «генеральную линию» перестройки, сформулированную в апреле 1985 года;

- отбросить социалистическую идеологию, ускоренно продвигаясь к демократии и рынку западного типа;

- продвигаться к рынку, не торопясь с введением политической демократии, проведением демократических реформ (то, что с известной долей условности получило название «китайского варианта»), а обветшавшую коммунистическую идеологию постепенно заменить социал-патриотической.

По сути, первые два варианта и были опробованы в перестройку и последующий политический период, а при Владимире Путине, в первое десятилетие его правления, страна пыталась испробовать как раз «третий» сценарий - авторитарной модернизации, развития рынка и экономического либерализма при одновременном сворачивании демократических процессов. Уже в постперестроечный период возобладала точка 
зрения, что всё же не следовало разрушать социализм, что перестройка не должна была выходить из рамок заявленных первоначально целей, определённых как обновление и демократизация социалистического строя.

На вопрос, какой социально-политической строй в наибольшей степени подходит для России, заданный в ходе исследования Института Социологии РАН о «Русской мечте», были получены следующие ответы. За рыночный капитализм высказались лишь 20 процентов опрошенных, за социализм, который был во времена СССР, - 16, а большинство - чуть более половины - выступают за строй, который бы совмещал в себе и социалистические, и рыночные отношения, его можно назвать «иным социализмом» [2].

В подобном противоречии находит своё отражение один из кардинальных аспектов проводившейся М. Горбачёвым перестройки. Идеи социал-демократии и гуманного социализма в интерпретации инициатора перестройки носили космополитический, вненациональный характер.

«Гуманизация» брежневского социализма сопровождалась ослаблением СССР, потом и России на международной арене, распадом государственности, активизацией националистических сил, преимущественно антирусской направленности. Сегодняшний магистральный запрос на социализм носит ярко выраженный социал-патриотический характер. Это уже не просто гуманистическая утопия, а строй, являющийся наиболее адекватной формой политической и экономической жизни для коренных народов России.

Всё это заставляет говорить о перестройке в широком смысле слова как о процессе незавершённом. Историческая перестройка, начатая М. Горбачёвым, возможно, и потерпела поражение, но поражение потерпели и иные попытки реформирования общества. За прошедшие более чем двадцать лет с начала преобразований советского общества страна так и не нашла собственного исторического пути, адекватного своему самосознанию, не построила ни национальной модели экономики, ни национальной модели демократии.

2. Инновационный марксизм Китая XXI века. Очень поучителен опыт государственного строительства КНР в сравнении с опытом развития постсоветского периода России. Так, первые годы после прихода к власти Коммунистическая партия Китая следовала общепринятым в то время принципам социалистического строительства - индустриализации, коллективизации и культур- ной революции. Были и обычные в таких случаях серьёзные ошибки и просчёты. Такие как народные коммуны, борьба с классовыми врагами, наконец, продолжавшаяся целых десять лет «культурная революция», которая ввергла страну в экономический и политический хаос.

Вместе с тем, как подчёркивают сегодня в Китае, было бы неправильно сводить весь первый период только к одним ошибкам - Китайская Народная Республика состоялась как независимое, сильное государство, уверенно заявившее о себе на международной арене [3].

На рубеже 70-80 годов XX в. руководство компартии сделало целый ряд принципиальных выводов относительно прошлого, настоящего и будущего. Это была программа социалистической именно социалистической! - модернизации.

Был сделан вывод о том, что развитие каждой страны, в данном случае Китая, имеет свою национальную специфику, определяемую её культурноисторическими особенностями.

В Китае не отказываются от изучения и использования экономического и политического опыта других стран, но только в том случае, если он, этот опыт, отвечает потребностям социально-экономического развития китайского государства. Сам стратегический курс китайского руководства носит название «политика реформ и открытости».

Тысячи граждан Китая получают профессиональную подготовку в зарубежных странах, для изучения иностранного опыта за границу регулярно выезжают работники государственных и партийных органов. В стране побывали сотни известных политиков, экономистов, учёных из многих стран мира, которые свободно излагали свои взгляды перед китайской аудиторией.

Однако решающая роль в принятии экономических и тем более политических решений принадлежит китайскому экспертному сообществу.

Сегодня в Китае допускается свободное обсуждение всех проблем, не разрешается только критика «четырех основных принципов» - руководство обществом со стороны компартии, курс на строительство социализма, руководящая роль марксистской идеологии, существование демократической диктатуры народа.

Китайцы отлично понимают, что жизнь не стоит на месте, что изменившаяся международная обстановка, охватившая весь мир глобализация требуют постоянного обновления теоретических положений марксизма. Китайские обществоведы 
исходят из того, что Маркс, Энгельс, Ленин, Сталин, Мао Цзэдун - не боги, а люди, которым свойственно ошибаться. Сегодня много говорится о «китайской мечте», смысл которой состоит в том, что следует стремиться сделать Китай мощным, процветающим, богатым государством. В выступлениях китайских руководителей почти не встречаются ссылки на классиков и Мао Цзэдуна, если кого и цитируют, то Дэн Сяопина.

В результате длительных обсуждений была сформулирована «концепция социализма с китайской спецификой», или «теория Дэн Сяопина». Это было новое, китайское, слово в теории и практике социализма.

Согласно этой концепции, само строительство социалистического общества занимает длительный исторический период - несколько десятилетий, а возможно, и столетий, во всяком случае, временные рамки этого периода не определены.

Перед китайскими обществоведами поставлена задача - создать инновационный марксизм, марксизм XXI века, который учитывал бы громадные изменения, произошедшие в мире и самом Китае.

3. Основные направления государственного строительства. Из разработанной «концепции социализма с китайской спецификой» вытекает целый ряд принципиальных положений относительно форм собственности в переходный период. Частная собственность объявлена равноправной формой наряду с государственной, общественной и кооперативной. Это зафиксировано не только в партийных документах, но и в конституции государства.

Полноправными участниками строительства социализма становятся предприниматели.

Одновременно в практику хозяйствования вошли методы рыночного регулирования экономики. Китайцы исходят из того, что это чисто технические средства, не имеющие отношения к типу общественного устройства - капиталистическому или социалистическому.

Частный капитал стал играть важную роль в целом ряде отраслей народного хозяйства. Однако стратегические отрасли экономики - железнодорожный и авиационный транспорт, нефтяные и газовые компании, предприятия по добыче природных ископаемых, например, угольные шахты, банки - продолжают оставаться в руках государства.

Во-вторых, приоритетный характер в государственных планах имеет развитие научных ис- следований. Китайская академия наук и Китайская академия общественных наук функционируют в нормальном, обычном режиме. В случае необходимости привлекаются иностранные специалисты для решения конкретных научных и производственных задач.

В-третьих, особый разговор о подготовке работников партийных и государственных органов. Проще говоря - чиновников. Действует широкая сеть партийных школ и административных институтов. Например, в Пекине кроме городской партшколы аналогичные учреждения существуют в каждом районе города и даже в некоторых крупных компаниях. В Центральной партийной школе проходят переподготовку и руководители высшего уровня - от секретарей провинциальных партийных комитетов до министров, от ректоров университетов до ответственных работников творческих союзов. Им читают лекции не только преподаватели школы, перед ними выступают высшие руководители страны.

Китайцы стремятся сочетать опытные и молодые кадры. Покончено с практикой «культурной революции», когда руководителями часто становились так называемые «кадровые работники - ракеты», не имевшие ни необходимого практического опыта, ни профессиональных знаний. Теперь, чтобы стать руководителем провинциального и тем более центрального уровня, необходимо иметь опыт низовой работы, поэтому среди министров и секретарей провинциальных партийных комитетов нет лиц моложе 40 лет, а среди членов Политбюро ЦК - моложе 50 лет.

В результате в Китае построена устойчивая властная вертикаль. Во-первых, принятие решений не зависит от одного человека - первого лица, как это было раньше. Во-вторых, существует широкий резерв для занятия руководящих должностей, в том числе самых высших. Коррупция объявлена главной угрозой для существования партии и государства, ведётся постоянная борьба с ней. Свидетельство тому - судебные процессы против руководителей государственных компаний, провинций и городов, крупных военных чинов, министров и даже членов Политбюро.

B-четвертых, следует подчеркнуть, что все принимаемые решения на государственном уровне являются результатом длительного и тщательного обсуждения экспертным сообществом, которое, как правило, предпочитает постепенный переход от более низкого к более высокому этапу развития. 
Например, сразу после окончания «культурной революции» был выдвинут курс на «восстановление социалистической плановой экономики», затем его сменило утверждение о необходимости внедрения рыночных механизмов при сохранении господствующей роли плана. Впоследствии стали говорить о сочетании плана и рынка и, наконец, о важной роли последнего в социалистической экономике.

И вот теперь, по прошествии тридцати лет, было заявлено о решающей роли рынка. И только сейчас становится возможным появление частных коммерческих банков. При этом значение государственного регулирования экономических процессов по-прежнему признаётся. Благодаря такому подходу удалось избежать роста цен и инфляции, характерных для российской экономики.

Китайские учёные, мягко выражаясь, скептически относятся к «шоковой терапии» Гайдара, отнюдь не считая его великим экономистом. Как мы уже отметили, из процесса приватизации были исключены предприятия стратегического характера.

В пятых, в Китае понимают, что политическая и, следовательно, экономическая стабильность во многом зависит от культурно-идеологической ситуации в стране. В этой связи большое внимание уделяется пропаганде в обществе идеологических стандартов и культурных норм, способствующих воспитанию патриотизма и единого понимания истории Китая и Китайской Народной Республики.

Об ошибках Мао Цзэдуна, особенно в последний период его жизни, говорят, но в то же время подчёркивают, что это были ошибки великого политического деятеля, великого революционера, которые во многом объясняются тем, что Коммунистической партии Китая приходилось решать труднейшие задачи, и поэтому ошибки Мао Цзэдуна были в какой-то степени неизбежны. Китайские коммунисты не собираются переписывать историю своей партии со всеми её достижениями и недостатками во имя конъюнктурных политических соображений или в угоду чьим-либо интересам.

В сущности, та модель социализма, которая в настоящее время строится в Китае, имеет мало общего с социалистическим строем, существовавшим в Советском Союзе. Прежде всего это относится к её экономической составляющей. Есть определённая специфика и в политическом режиме китайского общества, всё большую роль приобретает единый национальный фронт, в который кроме компартии входят не только руководимые ею общественные организации, но и восемь «демократических партий». Если раньше эти партии выполняли чисто декоративные функции, то теперь они начинают играть определённую роль в общественно-политической жизни: их представители занимают руководящие посты в органах власти, высших учебных заведениях, научных учреждениях. Два министра центрального правительства - не коммунисты.

В шестых. На Западе обвиняют китайское руководство в отсутствии в стране демократии. Однако критики не учитывают социально-экономических и культурно-исторических особенностей Китая, его национальной специфики. По мнению китайских экспертов, одной из главных причин распада Советского Союза являлась утрата КПСС контроля за идейно-политической ситуацией в стране в период перестройки, когда не давался отпор тотальной критике всей советской истории, утверждениям типа «берите суверенитета столько, сколько хотите».

Китайцы считают, что повторение в Китае опыта советской перестройки и особенно опыты либерального реформирования экономики, может привести к непоправимым последствиям. Коммунистическая партия Китая является несущей конструкцией политического режима, поэтому подрыв её авторитета будет означать конец политической стабильности в стране.

В седьмых. К началу реформ экономической системы китайское право, правовая система в целом оказалась в плачевном состоянии. Один из болезненных уроков, вынесенных из десятилетия «Культурной революции», заключается в признании важной роли права, закона для общей политической и экономической стабильности в обществе.

Отказ от принятия Гражданского кодекса в КНР не был импровизацией, с 1983 году началась разработка Общих положений гражданского права (ОПГН) КНР, который не случайно совпал с началом работы над программой экономической реформы (октябрь 1984). Именно в связи с принятием ОПГП появилось выражение «идти на двух ногах». ОПГП насчитывает 156 статей, которые сгруппированы в девять разделов.

Сторонники хозяйственного права в КНР полагали, что предметом регулирования этой отрасли должны стать общественные отношения, в которых проявляется фактор государственного регулирования, управления и контроля [4]. 


\section{Библиография:}

1. Межуев Б. «Перестройка-2». Опыт повторения. - М.: Издательство «Весь Мир», 2014. - 208 с.

2. Бызов Л. Перестройка наше прошлое или наше будущее? // Литературная газета. № 1-2 21-27 января 2015 г.

3. Буров В.Г. Китай и китайцы глазами российского ученого. - М., 2000. - С. 123.

4. Бушев А.Ю., Макарова О.А., Попондопуло В.Ф. Коммерческое право зарубежных стран / Под ред. В.Ф. Попондупуло. - СПб., 2003. С. 253.

5. Пилия Д.Э. Система и структура органов исполнительной власти Республики Абхазия // Административное и муниципальное право. - 2010. - 6. - С. 31 - 34.

6. Добрынин Н.М. Краткий очерк о судьбе российского конституционализма: о сущности, эволюции и неотложности конституционной реформы // Право и политика. - 2013. - 12. - C. 1737 - 1752. DOI: 10.7256/18119018.2013.12.10142.

7. Ф. К. Есиева Эволюция высших органов государственной власти на завершающем этапе развития советской государственности // Политика и Общество. - 2012. - 2. - С. 13 - 18.

8. Трощинский П.В. Основные этапы формирования современной правовой системы Китайской Народной Республики // Журнал зарубежного законодательства и сравнительного правоведения / Journal of foreighn legislation and comparative law. - 2012. - 4. - C. 69 - 79.

\section{References (transliterated):}

1. Mezhuev B. «Perestroika-2». Opyt povtoreniya. - M.: Izdatel'stvo «Ves' Mir», 2014. - 208 s.

2. Byzov L. Perestroika nashe proshloe ili nashe budushchee? // Literaturnaya gazeta. № 1-2 21-27 yanvarya 2015 g.

3. Burov V.G. Kitai i kitaitsy glazami rossiiskogo uchenogo. - M., 2000. - S. 123.

4. Bushev A.Yu., Makarova O.A., Popondopulo V.F. Kommercheskoe pravo zarubezhnykh stran / Pod red. V.F. Popondupulo. SPb., 2003. S. 253.

5. Piliya D.E. Sistema i struktura organov ispolnitel'noi vlasti Respubliki Abkhaziya // Administrativnoe i munitsipal'noe pravo. - 2010. - 6. - C. $31-34$.

6. Dobrynin N.M. Kratkii ocherk o sud'be rossiiskogo konstitutsionalizma: o sushchnosti, evolyutsii i neotlozhnosti konstitutsionnoi reformy // Pravo i politika. - 2013. - 12. - C. 1737 - 1752. DOI: 10.7256/1811-9018.2013.12.10142.

7. F. K. Esieva Evolyutsiya vysshikh organov gosudarstvennoi vlasti na zavershayushchem etape razvitiya sovetskoi gosudarstvennosti // Politika i Obshchestvo. - 2012. - 2. - C. $13-18$.

8. Troshchinskii P.V. Osnovnye etapy formirovaniya sovremennoi pravovoi sistemy Kitaiskoi Narodnoi Respubliki // Zhurnal zarubezhnogo zakonodatel'stva i sravnitel'nogo pravovedeniya / Journal of foreighn legislation and comparative law. 2012. - 4. - C. $69-79$. 